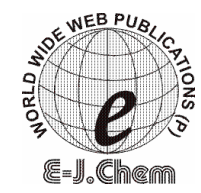

http://www.e-journals.net

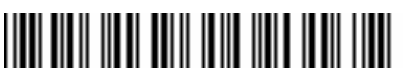

ISSN: 0973-4945; CODEN ECJHAO

E-Journal of Chemistry

Vol. 5, No. 1, pp. 43-51, January 2008

\title{
Kinetics of Oxidation of Cobalt(III) Complexes of $\alpha$-Hydroxy Acids by Hydrogen Peroxide in the Presence of Surfactants
}

\author{
MANSUR AHMED* and K. SUBRAMANI \\ Department of Chemistry, Islamiah College, Vaniyambadi-2, India. \\ chem_islamiah@fastmail.us
}

Received 5 April 2007; Accepted 20 July 2007

\begin{abstract}
Hydrogen peroxide oxidation of pentaamminecobalt(III) complexes of $\alpha$-hydroxy acids at $35{ }^{\circ} \mathrm{C}$ in micellar medium has been attempted. In this reaction the rate of oxidation shows first order kinetics each in [cobalt(III)] and $\left[\mathrm{H}_{2} \mathrm{O}_{2}\right]$. Hydrogen peroxide induced electron transfer in $\left[\left(\mathrm{NH}_{3}\right)_{5} \mathrm{CoIII}-\mathrm{L}\right]^{2+}$ complexes of $\alpha$-hydroxy acids readily yields $100 \%$ of cobalt(II) with nearly $100 \%$ of C-C bond cleavage products suggesting that it behaves mainly as one equivalent oxidant in micellar medium. With unbound ligand also it behaves only as $\mathrm{C}-\mathrm{C}$ cleavage agent rather than $\mathrm{C}-\mathrm{H}$ cleavage agent. With increasing micellar concentration an increase in the rate is observed.
\end{abstract}

Keywords: Sodium lauryl sulphate, Cetyl trimethyl ammonium bromide, Induced electron transfer micellar medium. Mandelicacid, Glycolicacid, Hydrogen peroxide.

\section{Introduction}

Oxidation is an important process in organic chemistry and us of new economic and effective oxidants under mild and anhydrous conditions constitutes a standing challenge. $\mathrm{H}_{2} \mathrm{O}_{2}$ is an oxidant ${ }^{1-3}$, which is non-hygroscopic non-photosensitive, stable yellow orange solid, freely soluble in water, acetic acid, $N, N$-dimethylformamide etc. Only few works have been done on $\mathrm{H}_{2} \mathrm{O}_{2}$ with cobalt(III) complexes as oxidant in micellar media ${ }^{4-6}$. A study of induced electron transfer reaction in $\mathrm{Co}(\mathrm{III})-\mathrm{L}$ system by an external oxidant is an aid. To classify the mode of action of the external oxidant, whether an one electron transfer takes place at the bound organic ligand or the bound organic ligand gets oxidized without disturbing $\mathrm{Co}(\mathrm{III})$ center. 


\section{Experimental}

The surfactants used in the present work are sodium lauryl sulphate ${ }^{6}$ (NaLS) and cetyl trimethyl ammonium bromide $^{7}(\mathrm{CTAB})$. The surfactants are purified by adopting earlier procedure ${ }^{8,9,10}$. Pentaamminecobalt(III) complexes of $\alpha$-hydroxyacids were prepared using 'Fan and Gould ${ }^{11}$. Double distilled (deionised and $\mathrm{CO}_{2}$ free) water was used as a solvent and $\mathrm{H}_{2} \mathrm{SO}_{4}$ was standardized using standard Sodiumcarbonate solution with methyl orange as indicator. For the $\mathrm{H}_{2} \mathrm{O}_{2}$ oxidation of $\mathrm{Co}(\mathrm{III})$ Complexes of $\alpha$-hydroxy acid and unbound ligands, the rate measurement were made at $35 \pm 0.2{ }^{\circ} \mathrm{C}$ in $100 \%$ aqueous micellar medium and temperature was controlled by electrically operated thermostat ${ }^{12}$. The total volume of reaction mixture in the spectrophotometric cell was kept as $2.5 \mathrm{~mL}$ in each kinetic run. A systronic spectrophotometer fitted with recording and thermostating arrangement was used to follow the rate of the reaction. Rate of these $\mathrm{H}_{2} \mathrm{O}_{2}$ oxidant with unbound ligand and cobalt(III) bound complexes were calculated from observed decrease in absorbance at $350 \mathrm{~nm}$ for oxidant, and $502 \mathrm{~nm}$ for cobalt(III) complexes.

Table 1. Stoichiometric data for $\mathrm{H}_{2} \mathrm{O}_{2}$ oxidation of $\mathrm{Co}$ (III) bound and unbound $\alpha$ - hydroxy acids in the presence of NALS.

\begin{tabular}{|c|c|c|c|c|}
\hline $\begin{array}{l}10^{3}[\text { Compound }] \\
\mathrm{mol} \mathrm{dm}^{-3}\end{array}$ & $\begin{array}{c}10^{2}\left[\mathrm{H}_{2} \mathrm{O}_{2}\right] \text { initial } \\
\text { mol } \mathrm{dm}^{-3}\end{array}$ & $\begin{array}{c}10^{2}\left[\mathrm{H}_{2} \mathrm{O}_{2}\right] \text { Final } \\
\text { mol dm}\end{array}$ & $\begin{array}{c}\Delta 10^{3}\left[\mathrm{H}_{2} \mathrm{O}_{2}\right] \\
\mathrm{mol} \mathrm{dm}^{-3}\end{array}$ & $\begin{array}{c}\text { [Compound] } \\
\Delta\left[\mathrm{H}_{2} \mathrm{O}_{2}\right]\end{array}$ \\
\hline \multicolumn{5}{|l|}{ Mandelic acid } \\
\hline 4.0 & 2.0 & 1.60 & 4.0 & $1.00: 1.00$ \\
\hline 5.0 & 2.0 & 1.55 & 4.5 & $1.00: 0.90$ \\
\hline 6.0 & 3.0 & 2.42 & 5.8 & $1.00: 0.98$ \\
\hline \multicolumn{5}{|l|}{ Lactic acid } \\
\hline 4.0 & 2.0 & 1.60 & 3.9 & $1.00: 0.97$ \\
\hline 5.0 & 2.0 & 1.51 & 4.9 & $1.00: 0.98$ \\
\hline 6.0 & 3.0 & 2.40 & 6.0 & $1.00: 1.00$ \\
\hline \multicolumn{5}{|l|}{ Glycolic acid } \\
\hline 4.0 & 2.0 & 1.60 & 4.0 & $1.00: 1.00$ \\
\hline 5.0 & 2.0 & 1.50 & 5.0 & $1.00: 1.00$ \\
\hline 6.0 & 3.0 & 2.42 & 5.8 & $1.00: 0.96$ \\
\hline \multicolumn{5}{|l|}{ Co(III)-Mandelato } \\
\hline 4.0 & 2.0 & 1.75 & 2.5 & $1.00: 0.60$ \\
\hline 5.0 & 2.0 & 1.71 & 2.9 & $1.00: 0.60$ \\
\hline 6.0 & 3.0 & 2.67 & 3.3 & $1.00: 0.65$ \\
\hline \multicolumn{5}{|l|}{ Co(III)-Lactato } \\
\hline 4.0 & 2.0 & 1.79 & 2.1 & $1.00: 0.52$ \\
\hline 5.0 & 2.0 & 1.74 & 2.6 & $1.00: 0.52$ \\
\hline 6.0 & 3.0 & 2.68 & 3.2 & $1.00: 0.53$ \\
\hline \multicolumn{5}{|l|}{ Co(III)-Glycolato } \\
\hline 4.0 & 2.0 & 1.80 & 2.0 & $1.00: 0.50$ \\
\hline 5.0 & 2.0 & 1.76 & 2.4 & $1.00: 0.48$ \\
\hline 6.0 & 3.0 & 2.70 & 3.0 & $1.00: 0.50$ \\
\hline
\end{tabular}

The excess of the reductant was used in kinetic runs. It gives pseudo first order. The rate constant was determined from the linear plot of the $\ln \mathrm{A}$ versus time. Reproducible result obtained giving good first order plot. The stoichiometric studies for the $\mathrm{H}_{2} \mathrm{O}_{2}$ oxidation of pentaammine 
cobalt(III) complexes of $\alpha$-hydroxyacid and unbound ligand in the presence of micelles were carried out at $35 \pm 0.2^{0} \mathrm{C}$. It was observed that the cobalt(II) formation was negligibly small.

\section{Stoichiometric studies}

The stoichiometic studies for the $\mathrm{H}_{2} \mathrm{O}_{2}$ oxidation of pentaamminecobalt(III) complexes of $\alpha$-hydroxy acids and unbound ligands in the presence of micelles (NaLS Table $1 \&$ CTAB Table 2) were carried out with oxidant in excess. The $\left[\mathrm{H}^{+}\right]$and ionic strength were maintained as in the corresponding rate measurements. The temperature was maintained at $35 \pm 0.2{ }^{\circ} \mathrm{C}$. After nine half lives when the reaction was nearing completion, the concentration of unreacted $\mathrm{H}_{2} \mathrm{O}_{2}$ was determined both iodometrically and spectrophoto metrically from the change in absorbance measured at $350 \mathrm{~nm} . \Delta \mathrm{H}_{2} \mathrm{O}_{2}$ was calculated after applying be blank corrections for decomposition of $\mathrm{H}_{2} \mathrm{O}_{2}$ and aquation of cobalt(III) complex of $\alpha$-hydroxy acids in the presence of micelles. Similar calculation about $\Delta\left[\mathrm{H}_{2} \mathrm{O}_{2}\right]$ was made for the unbound ligand also. The stoichiometry was calculated from the ratio between reacted [oxidant] and [substrate]. From the decrease in the absorbance measured for the cobalt(III) complex, the amount of cobalt(III) reduced was calculated. This value was then compare with the amount of cobalt(II) formed. Also $\mathrm{H}_{2} \mathrm{O}_{2}$ oxidation of $\mathrm{Co}$ (III) complexes of $\alpha$-hydroxy acids polymerization test done. It confirms the reaction proceeds through radical path way.

Table 2. Stoichiometric data for BPC oxidation of $\mathrm{Co}(\mathrm{III})$ bound and unbound $\alpha$-hydroxy acids in the presence of CTAB.

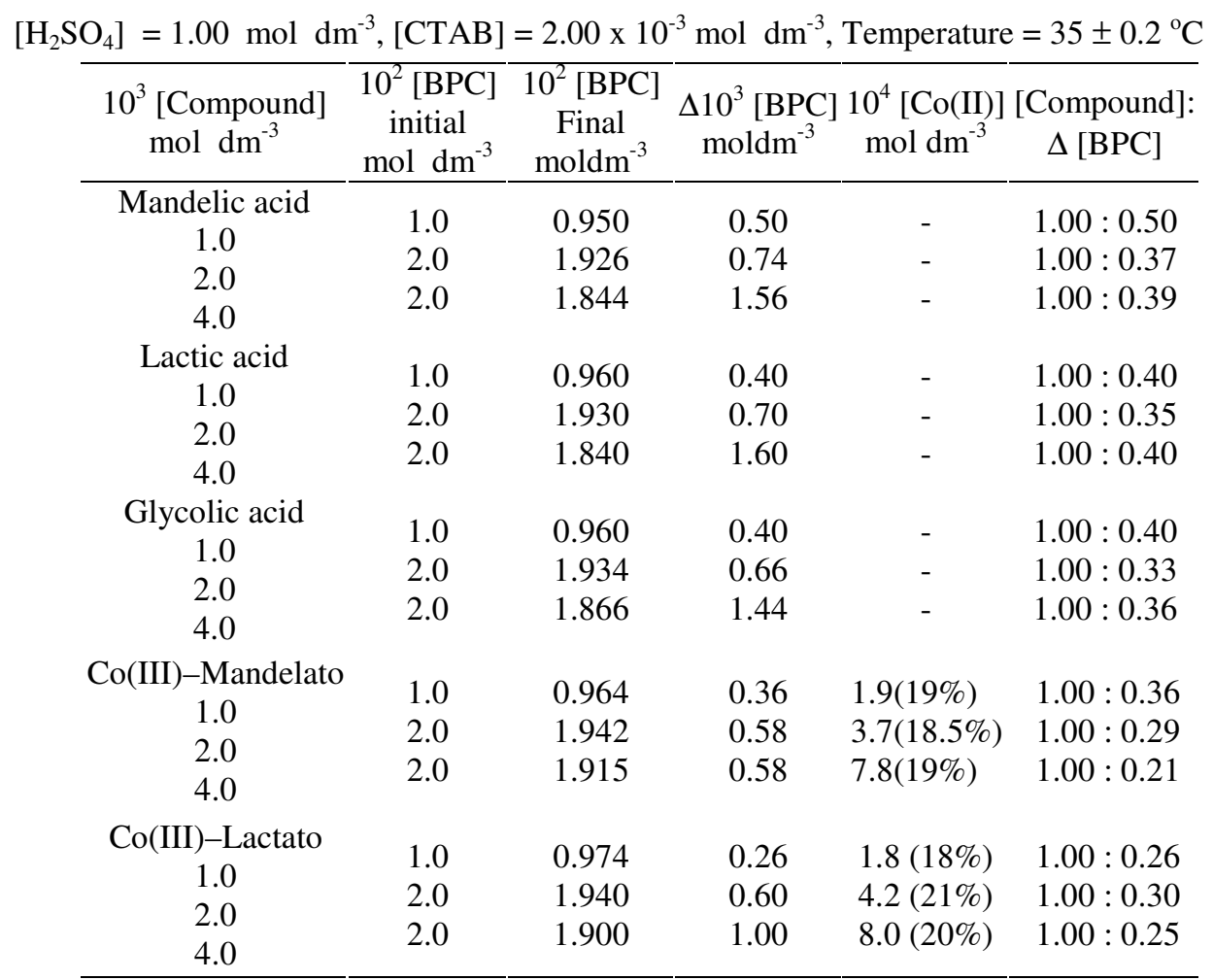




\section{Results and Discussion}

\section{Dependence of rate on $\mathrm{H}_{2} \mathrm{O}_{2}$ concentration in micellar bound ligand.}

The rate of oxidation of mandelato, lactato and glycolatocobalt(III) complexes depends on $\mathrm{H}_{2} \mathrm{O}_{2}$ concentration. In any specific run, the specific rates calculated remains constant (Table 3) and graph of logarithm of $\mathrm{H}_{2} \mathrm{O}_{2}$ concentration versus time (Figure 1) are linear. From the slope of these graphs, the specific rate calculated agrees with those obtained from integrated rate equation suggesting first order dependence on $\mathrm{H}_{2} \mathrm{O}_{2}$ concentration. This is further substantiated from the study of the effect of changing $\mathrm{H}_{2} \mathrm{O}_{2}$ concentration on the rate of oxidation. The constancy in the specific rates of oxidation of mandelato, lactato and glycolato cobalt(III) complexes, is in keeping with the first order dependence on $\mathrm{H}_{2} \mathrm{O}_{2}$ concentration. The rate law is given by Eq.1

$$
-\mathrm{d}\left[\mathrm{H}_{2} \mathrm{O}_{2}\right] / \mathrm{dt}=\mathrm{k}_{1}\left[\mathrm{H}_{2} \mathrm{O}_{2}\right]
$$

Table 3. First order values for $\mathrm{H}_{2} \mathrm{O}_{2}$ oxidation of cobalt(III) bound Ligand. $\left[\left(\mathrm{NH}_{3}\right)_{5} \mathrm{Co}^{\mathrm{III}}-\mathrm{L}\right]^{2+}=2.00 \times 10^{-2} \mathrm{~mol} \mathrm{dm}^{-3},\left[\mathrm{H}_{2} \mathrm{O}_{2}\right]=2.00 \times 10^{-3} \mathrm{~mol} \mathrm{dm}^{-3}$, $\left[\mathrm{H}_{2} \mathrm{SO}_{4}\right]=1.00 \mathrm{~mol} \mathrm{dm}^{-3}$, [ Na LS $]=[\mathrm{CTAB}]=2.00 \times 10^{-3} \mathrm{~mol} \mathrm{dm}^{-3}$,

Temperature $=35 \pm 0.2{ }^{0} \mathrm{C}, \mathrm{L}=$ mandelato.

\begin{tabular}{ccc}
\hline Time & \multicolumn{2}{c}{$10^{3}(\mathrm{a}-\mathrm{x}), \mathrm{mol} \mathrm{dm}^{-3}$} \\
\cline { 2 - 3 } $\mathrm{s}$ & $\mathrm{NaLS}$ & $\mathrm{CTAB}$ \\
\hline 300 & 1.60 & 1.39 \\
600 & 1.26 & 0.96 \\
900 & 1.00 & 0.66 \\
1200 & 0.80 & 0.47 \\
1500 & 0.63 & 0.32 \\
1800 & 0.49 & 0.23 \\
2100 & 0.41 & 0.16 \\
2400 & 0.33 & 0.11 \\
2700 & 0.26 & 0.08 \\
\hline
\end{tabular}

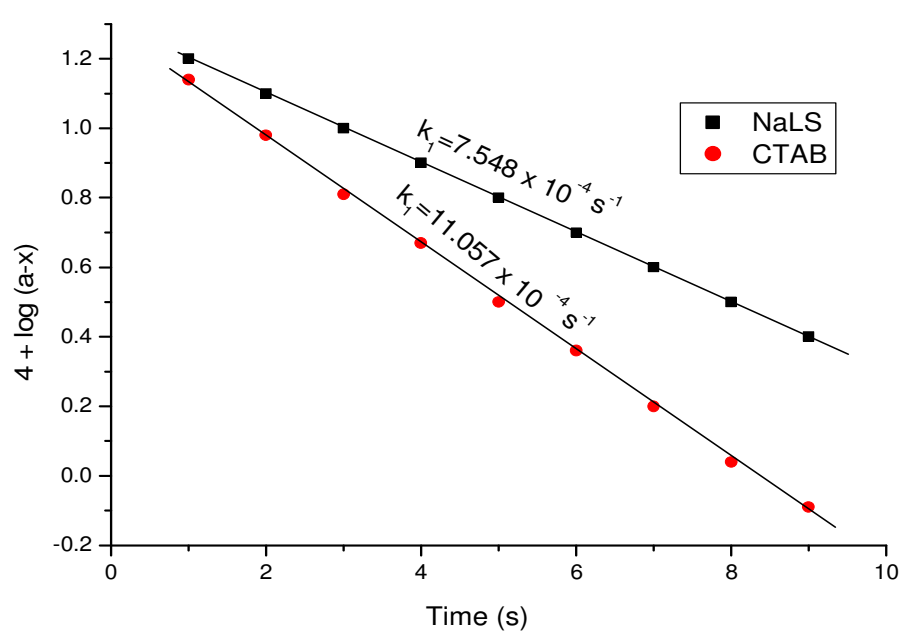

Figure 1. First order dependence plots. 


\section{Dependence of rate on the concentration of cobalt(III) bound $\alpha$-hydroxy acids}

At a particular $\mathrm{H}_{2} \mathrm{O}_{2}$ concentration with increases in manlato/lactato/glycolato cobalt(III) concentration in the range 1.00 to $3.00 \times 10^{-3} \mathrm{~mol} \mathrm{dm}^{-3}$ there is a proportional increases in the rate of oxidation (Table $4 \& 5$ ), as shown by the correlation coefficients of $0.9992,0.9998$ and 0.9996 for the above respective complexes in anionic micelles. The slope of nearly unity is obtained from a linear graph of logarithm of specific rate $\left(\mathrm{k} \mathrm{in} \mathrm{s}^{-1}\right)$ versus logarithm of $\mathrm{Co}$ (III) concentration in each case suggesting first order rate dependence of rate on [Co(III)] (Figures 2 \& 3). Hence the rate law for the $\mathrm{H}_{2} \mathrm{O}_{2}$ oxidation of cobalt(III) bound of $\alpha$-hydroxy acids are given by Eq. 2

$$
-\mathrm{d}\left[\mathrm{H}_{2} \mathrm{O}_{2}\right] / \mathrm{dt}=\mathrm{k}_{2}\left[\mathrm{H}_{2} \mathrm{O}_{2}\right][\mathrm{Co}(\mathrm{III})]
$$

Table 4. First order values of the concentration of cobalt(III) bound $\alpha$-hydroxy acids in NaLS. $\left[\mathrm{H}_{2} \mathrm{O}_{2}\right]=2.00 \times 10^{-3} \mathrm{~mol} \mathrm{dm}^{-3},\left[\mathrm{H}_{2} \mathrm{SO}_{4}\right]=1.00 \mathrm{~mol} \mathrm{dm}^{-3}[\mathrm{Na} \mathrm{LS}]=2.00 \times 10^{-3} \mathrm{~mol} \mathrm{dm}^{-3}$ Temperature $=35 \pm 0.2^{0} \mathrm{C}$.

\begin{tabular}{ccc}
\hline $\begin{array}{c}\left.\left(\mathrm{NH}_{3}\right)_{5} \mathrm{Co}{ }^{\mathrm{III}}-\mathrm{L}\right], \\
\mathrm{mol} \mathrm{dm}^{-3}\end{array}$ & $\begin{array}{c}10{ }^{4} \mathrm{k}_{1}, \\
\mathrm{~s}^{-1}\end{array}$ & $\begin{array}{c}10^{2} \mathrm{k}_{2} \\
\mathrm{dm}^{3} \mathrm{~mol}^{-1} \mathrm{~s}^{-1}\end{array}$ \\
\hline $\mathrm{L}=$ Mandelacto & & \\
1.00 & 3.80 & 3.80 \\
1.50 & 5.81 & 3.87 \\
2.00 & 7.62 & 3.81 \\
2.50 & 9.60 & 3.84 \\
3.00 & 11.60 & 3.87 \\
$\mathrm{~L}=$ Lactato & & \\
1.00 & 4.40 & 4.40 \\
1.50 & 6.82 & 4.55 \\
2.00 & 8.90 & 4.45 \\
3.00 & 13.40 & 4.47 \\
$\mathrm{~L}=$ Glycolato & & \\
1.00 & 2.51 & 2.51 \\
2.50 & 6.35 & 2.54 \\
3.00 & 7.84 & 2.61 \\
\hline
\end{tabular}

Table 5. First order values of the concentration of cobalt (III) bound $\alpha$-hydroxy acids in CTAB. $\left[\mathrm{H}_{2} \mathrm{O}_{2}\right]=2.00 \times 10^{-3} \mathrm{~mol} \mathrm{dm}^{-3},\left[\mathrm{H}_{2} \mathrm{SO}_{4}\right]=1.00 \mathrm{~mol} \mathrm{dm}^{-3},[\mathrm{CTAB}]=2.00 \times 10^{-3} \mathrm{~mol} \mathrm{dm}^{-3}$ Temperature $=35 \pm 0.2{ }^{\circ} \mathrm{C}$

\begin{tabular}{ccc}
\hline $10^{2}\left[\begin{array}{cc}\left.\left(\mathrm{NH}_{3}\right)_{5} \mathrm{Co}^{\mathrm{III}}-\mathrm{L}\right] \\
\mathrm{mol} \mathrm{dm}^{-3}\end{array}\right.$ & $\begin{array}{c}10^{4} \mathrm{k}_{1} \\
\mathrm{~s}^{-1}\end{array}$ & $\begin{array}{c}10^{2} \mathrm{k}_{2} \\
\mathrm{dm}^{3} \mathrm{~mol}^{-1} \mathrm{~s}^{-1}\end{array}$ \\
\hline $\mathrm{L}=$ Mandelacto & & \\
1.00 & 6.2 & 6.20 \\
2.00 & 12.1 & 6.05 \\
2.50 & 15.7 & 6.28 \\
3.00 & 18.2 & 6.06 \\
$\mathrm{~L}=$ Lactato & & \\
1.00 & 7.2 & 7.20 \\
1.50 & 10.7 & 7.13 \\
2.00 & 14.5 & 7.25 \\
3.00 & 21.2 & 7.06 \\
$\mathrm{~L}=$ Glycolato & & \\
1.00 & 4.70 & 4.70 \\
1.50 & 7.22 & 4.81 \\
2.00 & 9.70 & 4.85 \\
2.50 & 11.90 & 4.76 \\
\hline
\end{tabular}




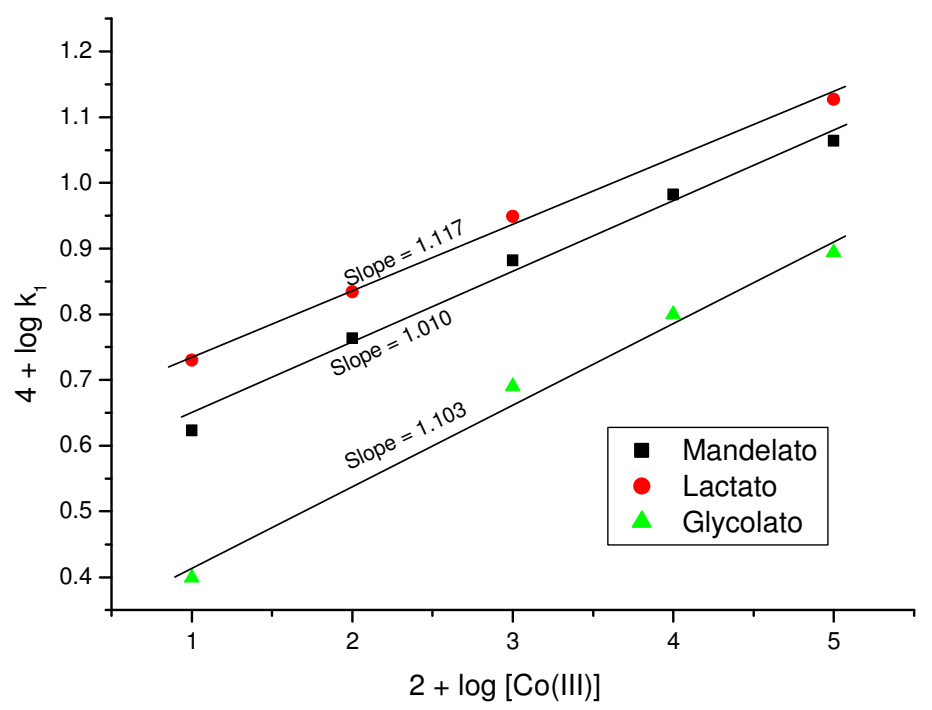

Figure 2. Dependence of rate on $[\mathrm{Co}(\mathrm{III})]$ in $\mathrm{NaLS}$

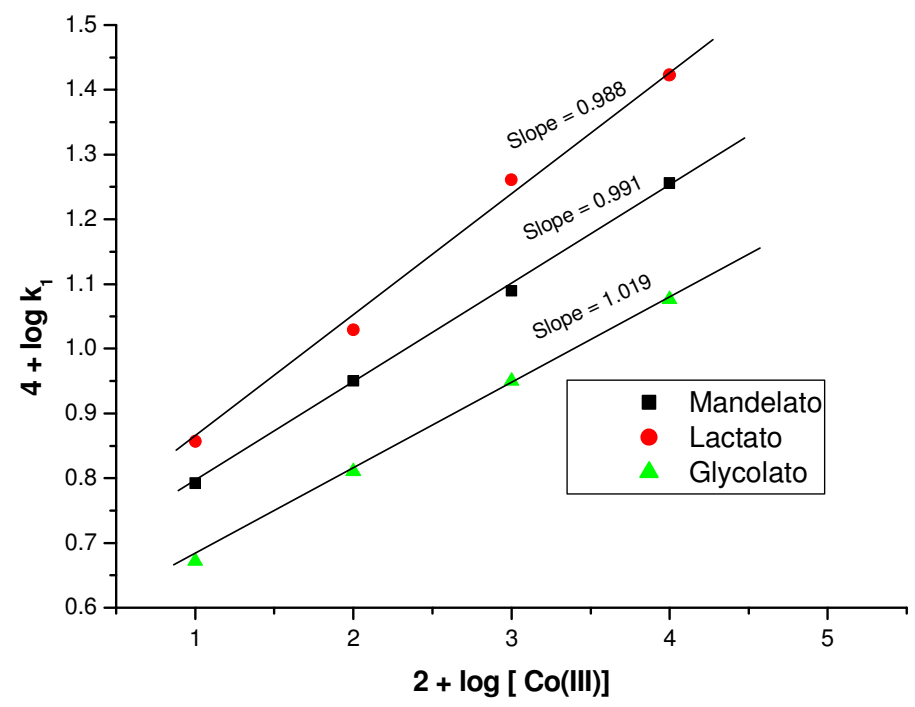

Figure 3. Dependence of rate on $[\mathrm{Co}(\mathrm{III})]$ in $\mathrm{CTAB}$

\section{Dependence of rate on $\alpha$-hydroxyacid concentration}

Under identical conditions, the effect of changing unbound $\alpha$-hydroxyacid concentration has been studied in the range 1.00 to $3.00 \times 10^{-2} \mathrm{~mol} \mathrm{dm}^{-3}$ with all these substrates in micellar medium. 
There is a monotonic increase in the rate of $\mathrm{H}_{2} \mathrm{O}_{2}$ oxidation with unbound $\alpha$-hydroxyacid with increase concentration of substrate (Table $3 \& 4$ ), as shown by the correlation coefficients of 0.9996. Also a graph of logarithm of specific rate $\left(\mathrm{k}_{1}\right.$ in s$\left.{ }^{-1}\right)$ versus logarthim of $\alpha$-hydroxyacid concentration is linear with a slope nearly equal to unity (Figure 6\&7) with each one of he substrates and therefore, the rate law for the $\mathrm{H}_{2} \mathrm{O}_{2}$ oxidation of unbound $\alpha$-hydroxyacid which is similar to cobalt(III) bound ligands, is given Eq. 3 .

$$
-\mathrm{d}\left[\mathrm{H}_{2} \mathrm{O}_{2}\right] / \mathrm{dt}=\mathrm{k}_{2}\left[\mathrm{H}_{2} \mathrm{O}_{2}\right] \text { [ } \alpha \text {-hydroxyacid ] }
$$

Table 6. First order values of the concentration of $\alpha$-hydroxy acids in NaLS $\left[\mathrm{H}_{2} \mathrm{O}_{2}\right]=2.00 \times 10^{-3} \mathrm{~mol} \mathrm{dm}^{-3},\left[\mathrm{H}_{2} \mathrm{SO}_{4}\right]=1.00 \mathrm{~mol} \mathrm{dm}^{-3},[\mathrm{Na} \mathrm{LS}]=2.00 \times 10^{-3} \mathrm{~mol} \mathrm{dm}^{-3}$ Temperature $=35 \pm 0.2{ }^{0} \mathrm{C}$

\begin{tabular}{ccc}
\hline $\begin{array}{c}10^{2}[\alpha \text {-hydroxy acid }] \\
\text { mol dm }\end{array}$ & $\begin{array}{c}10^{4} \mathrm{k}_{1} \\
\mathrm{~s}^{-1}\end{array}$ & $\begin{array}{c}10^{2} \\
\mathrm{dm}^{3} \mathrm{~mol}^{-1} \mathrm{~s}^{-1}\end{array}$ \\
\hline $\begin{array}{c}\text { Mandelic acid } \\
1.00\end{array}$ & 1.62 & 1.62 \\
1.50 & 2.43 & 1.62 \\
2.00 & 3.28 & 1.67 \\
2.50 & 4.16 & 1.66 \\
3.00 & 4.89 & 1.63 \\
Lactic acid & & \\
1.00 & 2.23 & 2.23 \\
1.50 & 3.41 & 2.27 \\
2.00 & 4.51 & 2.25 \\
2.50 & 5.63 & 2.26 \\
3.00 & 6.92 & 2.20 \\
Glycolic acid & & \\
1.00 & 1.36 & 1.36 \\
2.00 & 2.82 & 1.41 \\
2.50 & 3.55 & 1.42 \\
3.00 & 4.18 & 1.39 \\
\hline
\end{tabular}

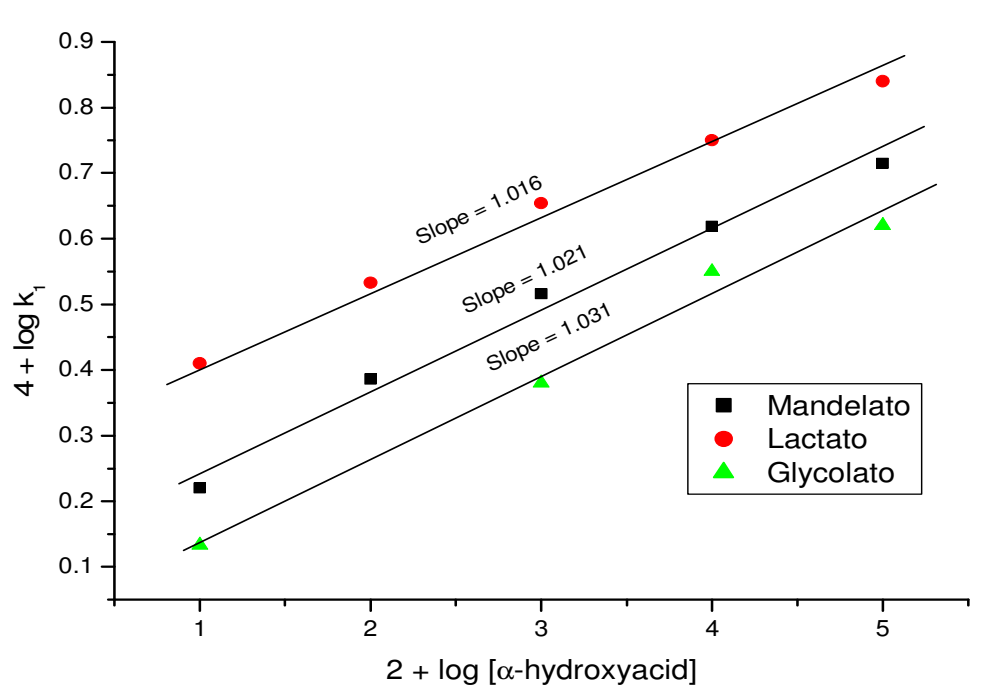

Figure 4. Dependence of rate on [ $\alpha$-hydroxyacid ] in NaLS 
Table 7. First order values of the concentration of $\alpha$-hydroxy acids in CTAB $\left[\mathrm{H}_{2} \mathrm{O}_{2}\right]=2.00 \times 10^{-3} \mathrm{~mol} \mathrm{dm}^{-3},\left[\mathrm{H}_{2} \mathrm{SO}_{4}\right]=1.00 \mathrm{~mol} \mathrm{dm}^{-3},[\mathrm{CTAB}]=2.00 \times 10^{-3} \mathrm{~mol} \mathrm{dm}^{-3}$ Temperature $=35 \pm 0.2{ }^{\circ} \mathrm{C}$.

\begin{tabular}{ccc}
\hline $\begin{array}{c}10^{2}\left[\begin{array}{c}1 \\
\text { mol dm }\end{array}\right. \\
\text { Mandelic acid }\end{array}$ & $\begin{array}{c}10^{4} \mathrm{k}_{1} \\
\mathrm{~s}^{-1}\end{array}$ & $\begin{array}{c}10^{2} \mathrm{k}_{2} \\
\mathrm{dmol}^{-1} \mathrm{~s}^{-1}\end{array}$ \\
1.00 & 2.06 & 2.06 \\
1.50 & 3.13 & 2.08 \\
2.00 & 4.18 & 2.09 \\
2.50 & 5.26 & 2.10 \\
Lactic acid & & \\
1.00 & 3.02 & 3.02 \\
1.50 & 4.61 & 3.07 \\
2.00 & 6.12 & 3.06 \\
3.00 & 9.24 & 3.08 \\
Glycolic acid & & \\
1.00 & 1.93 & 1.93 \\
1.50 & 2.98 & 1.98 \\
2.00 & 3.95 & 1.97 \\
2.50 & 4.86 & 1.94 \\
\hline
\end{tabular}

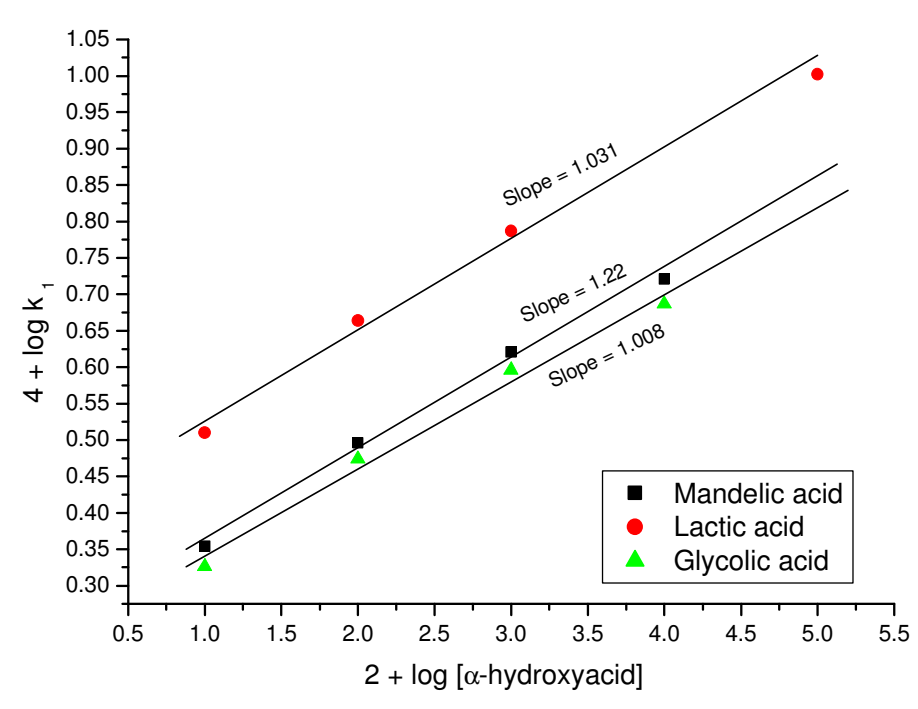

Figure 5. Dependence of rate on [ $\alpha$-hydroxyacid ] in CTAB

Comparison of rates on oxidation of pentaamminecobalt(III) complexes of both bound and unbound $\alpha$-hydroxyacid by $\mathrm{H}_{2} \mathrm{O}_{2}$.

The cobalt(III) lactato complex is faster than cobalt(III) mandelato and cobalt(III)glycolato complex, because if the reaction proceeds through a performed radical, then the rate of $\mathrm{C}-\mathrm{H}$ cleavage should be enhanced, resulting in a increase in the rate of oxidation of cobalt(III) complex. At the same concentration added CTAB enhances the rate of oxidation of reaction much more than added NaLS. Bothe cationic and anionic micelles act as positive catalyst, 
a neutral reaction $\mathrm{H}_{2} \mathrm{O}_{2}$ species is involved in the oxidation. If the reaction species is ionic the reaction, would have been accelerated in one detergent and retarded in the other depending on the charge carried by it.

\section{Mechanism}

Oxidation of pentaamminecobalt(III) complexes of both bound and unbound ligands in micellar medium. The features of hydrogen peroxide induced electron transfer in pentaamminecobalt(III) complexes of $\alpha$-hydroxyacid are summarized as below.
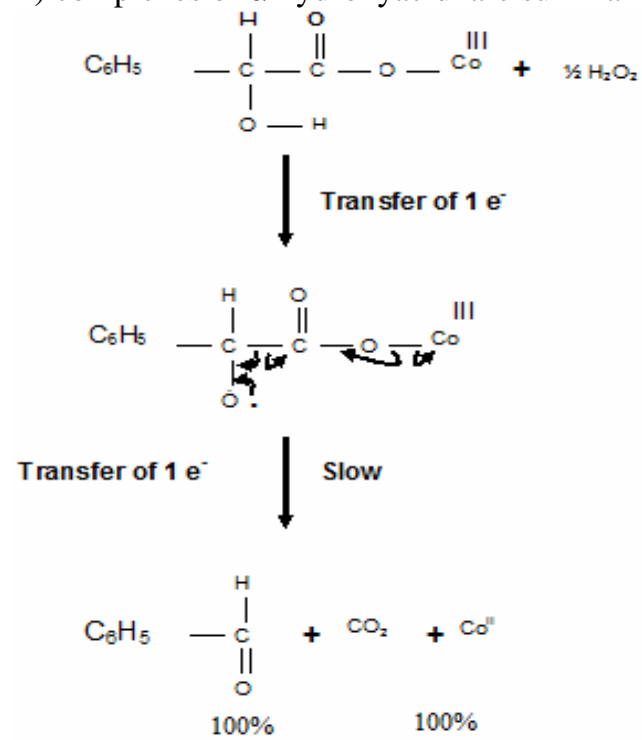

\section{Conclusion}

The kinetics of one electron transfer route seems to be available for $\mathrm{H}_{2} \mathrm{O}_{2}$ with cobalt(III) bound and unbound complexes of $\alpha$-hydroxyacid in micellar medium, $\mathrm{H}_{2} \mathrm{O}_{2}$ oxidizes cobalt(III) bound and unbound $\alpha$-hydroxyacids. It explains the synchronous $\mathrm{C}-\mathrm{C}$ bond fission and electron transfer to cobalt(III) centre. Oxidation of above complexes increases with increase of temperature. With increase in micellar concentration an increase in the rate is observed. The added CTAB enhances the rate of oxidation of a reaction much more than NaLS. Similar trends has been observed in lactato and glycolato co(III) complexes.

\section{References}

1. Baloj kawle, Thirupathi Rao M and Adinarayan M, Indian J. Chem., 1994, 33A, 1021.

2. Gurumurthy R, Karthikayan B and Selvaraju M, Oriental, J. of Chem. 1998, 14.

3. Kirti Chodhary Pradeep K, Sharma and Kalyan K Banerji, Indian J. Chem.,1999, 38A, 325.

4. Sandaran K R and Anbuselvan C, Asian. J. Chem., 1998,10 (4), 806.

5. $\quad$ Pandurangan A and Murugesan V, J. Indian Chem. Soc., 1996, 73. 484.

6. Thangaraj A and Gopalan, R., J. Indian Chem.Soc., 1996, 67, 453.

7. Long J, Auborn J J and Eyring F M J, Colloid, Interface Sci., 1973, 41, 457.

8. Yasunaga J, Takeda K and Harada S, J. Colloid, Interface, Sci., 1973,42, 457.

9. Mohantly N K and Nanda P K, Indian J. Chem, 1982, 21 A, 522.

10. Dash A G Nanda R K and Mohanti P, Indian, J. Chem., 1984, 23 A, 162.

11. Fan F R F and Gould E S, Inorg. Chem., 1974, 13, 2639.

12. Kabir-Ud-Din S M, Shakeel Iqubal, and Zaheer Khan, Indian, J. Chem, 2005, 44 A,2455. 


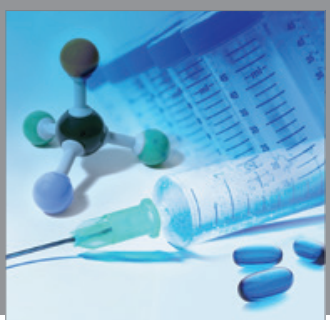

International Journal of

Medicinal Chemistry

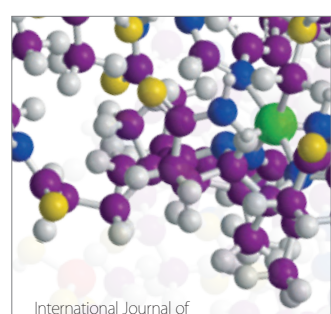

Carbohydrate Chemistry

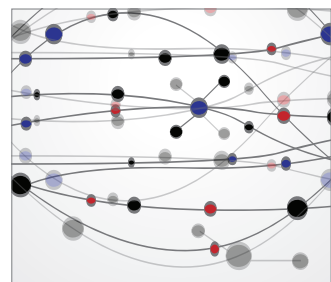

The Scientific World Journal
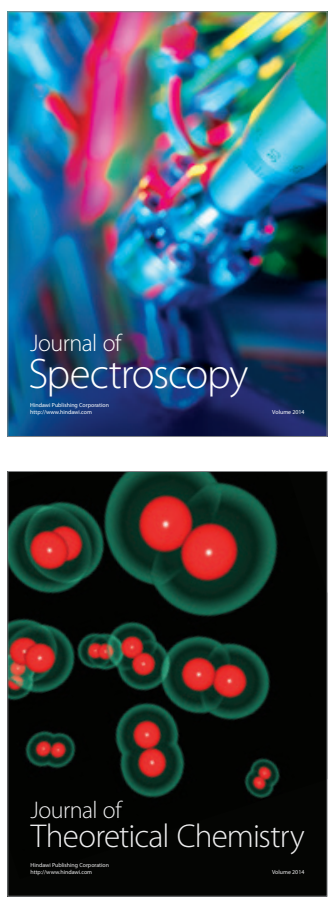
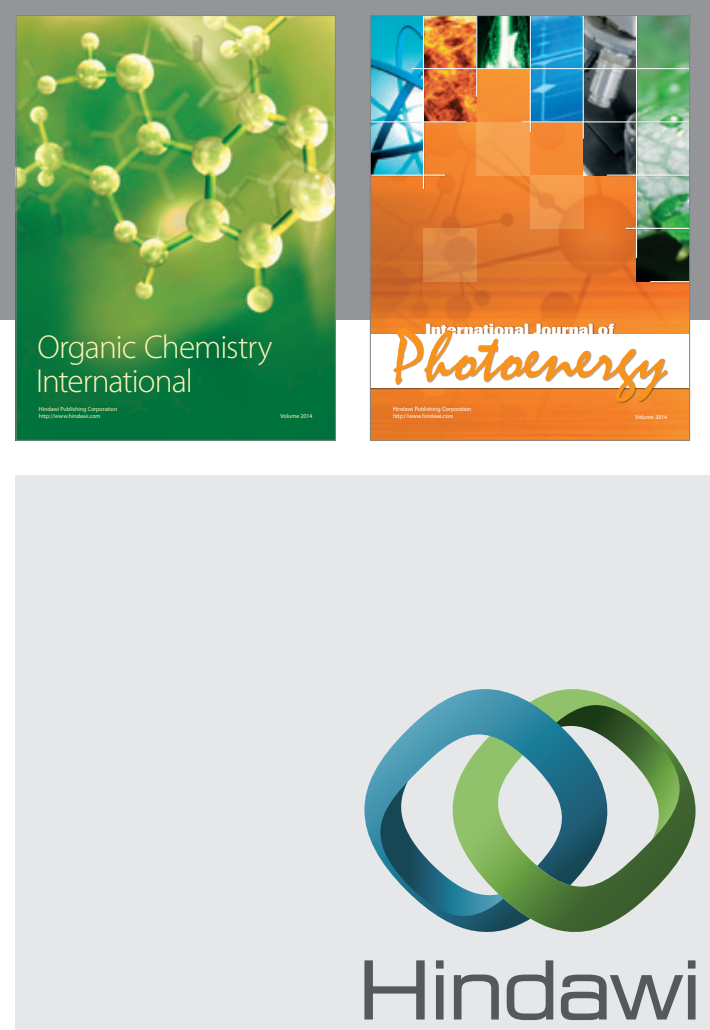

Submit your manuscripts at

http://www.hindawi.com
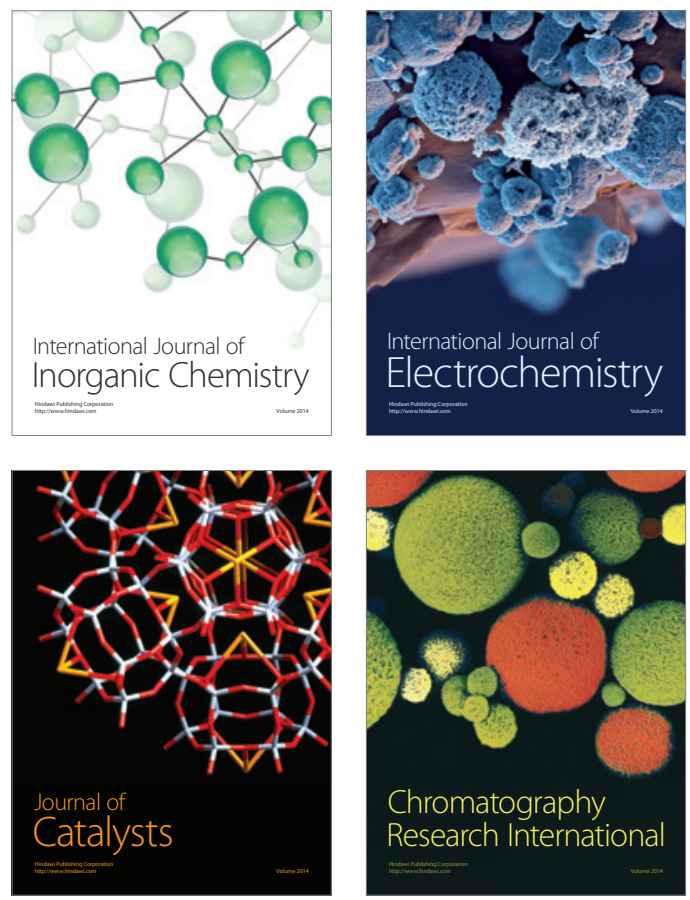
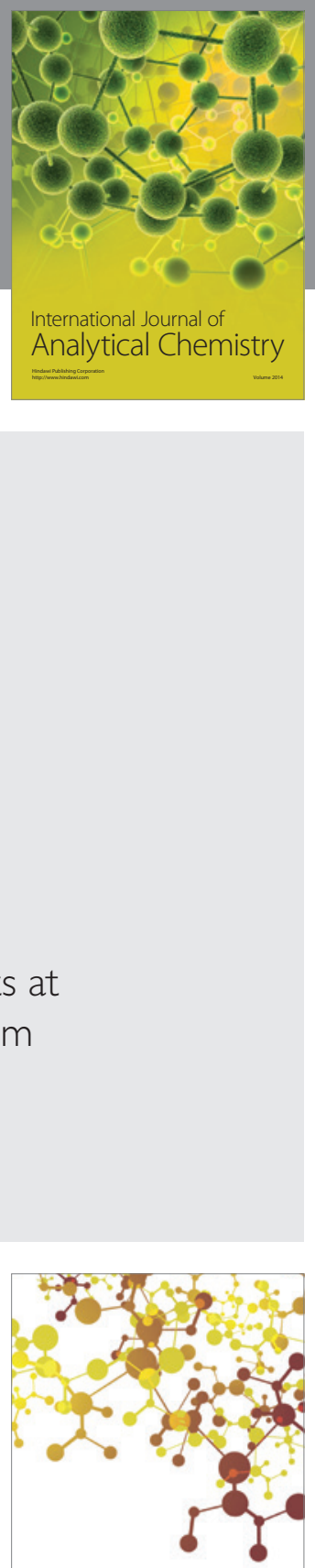

Journal of

Applied Chemistry
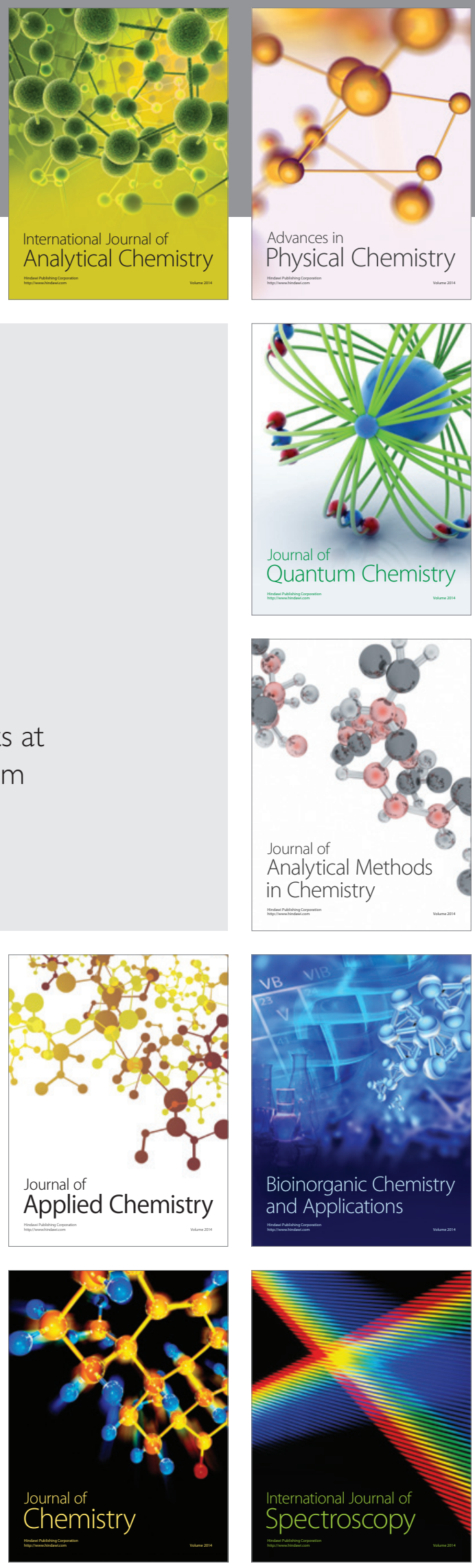